\title{
An Adult Filarial Worm in the Testicular Tissue: A Case Report
}

\author{
${ }^{1}$ Ashwin P Surhonne, ${ }^{2}$ Sharmila P Surhonne
}

\begin{abstract}
Filariasis is a tropical infectious disease and a global public health problem with high incidence in the Indian subcontinent. The clinical manifestations of filariasis vary from person to person depending upon course of infection and the worm load. It is very rare to observe adult filarial worm in the testicular tissues. We herewith report a case of adult filarial worm in the testicular tissue.
\end{abstract}

Keywords: Filariasis, Swelling, Testis

How to cite this article:, Surhonne AP, Surhonne SP. An Adult Filarial Worm in the Testicular Tissue: A Case Report. Int J Med Sci 2018;4(3):83-84.

\section{Source of support: Nil}

Conflict of interest: None

\section{INTRODUCTION}

Filariasis is an endemic parasitic infection commonly seen in tropical and subtropical regions. ${ }^{1,2}$ The disease mainly involves a lymphatic system of the body. Usually the term "filariasis" refers to lymphatic filariasis (LF) ${ }^{1,2}$ In India, heavily infected areas are found in Orissa, Uttar Pradesh, Bihar, Andhra Pradesh, Tamil Nadu, Kerala, and Gujarat. Lymphatic filariasis is caused by Wuchereria bancrofti and Brugia malayi. ${ }^{1,2}$ In male the genital filariasis more commonly presents as a secondary hydrocele with an associated epididymo-orchitis. ${ }^{3}$ It is very uncommon to find adult worm in the testis. We report this rare presentation of an adult worm within the testicular tissue.

\section{CASE HISTORY}

A 30-year young man presented with a history of swelling since 1 month and pain in his right scrotum since 6 days. The patient was afebrile and asymptomatic one month back. He had trauma to scrotal region followed by enlargement. Examination of the genitalia revealed a right testicle swelling. The left testis and

\footnotetext{
${ }^{1}$ Undergraduate Student, ${ }^{2}$ Professor and HOD

${ }^{1}$ Oxford Medical College, Bengaluru, Karnataka, India

${ }^{2}$ Department of Pathology, RajaRajeswari Medical College, Bengaluru, Karnataka, India

Corresponding Author: Sharmila P Surhonne, Professor and HOD, Department of Pathology, RajaRajeswari Medical College, Bengaluru, Karnataka, India, e-mail: ashwin.ashwin45@gmail. com
}

both spermatic cord were normal. Radiological and ultrasonological examination of genitalia was normal. Hematological and biochemical parameters were within normal range. No eosinophilia was seen in the peripheral blood. The clinical diagnosis of torsion or neoplastic lesion of testis was made. As the swelling was very painful, the patient underwent a right orchiectomy. The specimen sent for histopathological examination in $10 \%$ formalin. On examination entire right testis was dark brown with the peripheral rim of viable grey white tissue together measured $8 \mathrm{~cm} \times 4 \mathrm{~cm} \times 2 \mathrm{~cm}$. The epididymis and cord were normal. There was no associated hydrocele. Histopathological examination showed scanty rim of testicular tissue with extensive area of hemorrhage and necrosis, adult filarial worm (Fig. 1) surrounded by dense inflammatory cell infiltration of neutrophils, lymphoplasmocytes, and eosinophils along with features of funniculitis. No significant pathology was detectable in epididymis or spermatic cord. A histopathological diagnosis of right-sided filarial orchitis with funniculitis was given.

\section{DISCUSSION}

Filariasis is a worldwide public health problem caused by parasite $W$. bancrofti, B. malayi filariasis is transmitted by the bite of infected vector female mosquitoes of the Culex, Aedes, and Anopheles genera act as intermediate hosts. ${ }^{1-3}$ In male, there is a preference for the lymphatics of the spermatic cord, where the death of adult worms induce the inflammatory response in the form of suppuration to granulomatous simulating to neoplasm. ${ }^{4}$ Patient may acquire an infection in the childhood period and may

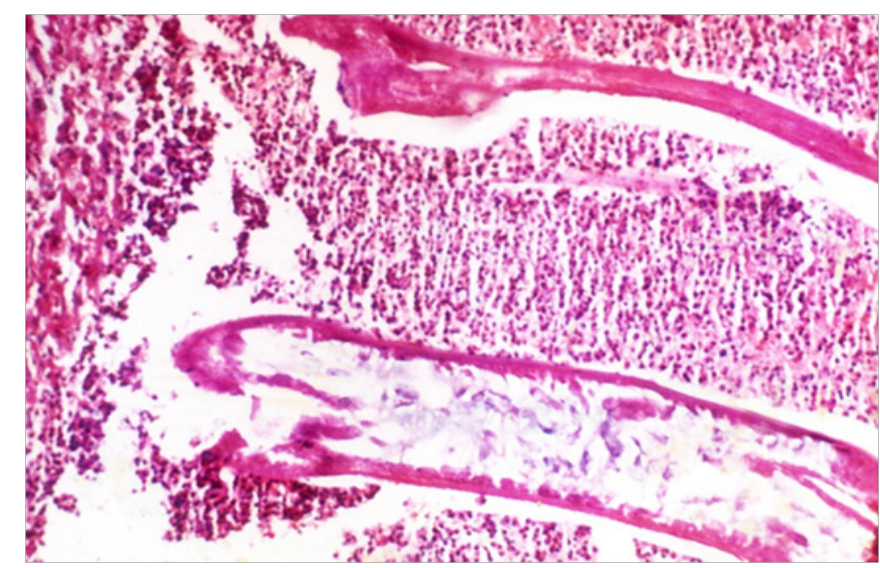

Fig. 1: Photomicrograph showing adult filarial worm within mixed inflammatory exudate $(4 \mathrm{x}, \mathrm{H}$ and $\mathrm{E})$ 
remain asymptomatic for longer duration or progresses to an overt clinical presentation of adults that involve male genitalia. ${ }^{5}$

The clinical manifestations of filariasis depend upon the stage of infection varies from lymphatic invasion to acute or chronic inflammation. ${ }^{4,5}$ These manifestations include funiculoepididymitis, orchitis, filarial abscess, oringuinal lymphadenitis, hydrocoele, lymph varix, lymph scrotum, filarial penis or elephantiasis of the genitalia, and chyluria or filarial granuloma. ${ }^{3-7}$ Secondary hydrocoele develops because of the above genital manifestations. $3,4,6$

The diagnosis is made on a clinical basis in the endemic areas. Tissue eosinophilia is a useful diagnostic clue. ${ }^{2}$ Identification of microfilarae in the peripheral blood in midnight smear is necessary for diagnosis. Antigen test using enzyme-linked immunosorbent assay (ELISA) technique is regarded as the gold standard for diagnosing filarial infection. The microfilariae can be seen on microscopic examination of fine-needle aspirates from lesions of lymph nodes, breast mass, thyroid mass, hydrocoele fluid, pericardial fluid, pleural fluid, ascitic fluid, and cytology of cervicovaginal smears, bronchial aspirates, urine, nipple secretion, bone marrow, and joint fluid aspirates. ${ }^{8}$ Adult worms had been found in lymphatics, subcutaneous tissue, peritoneal, and pleural cavities, heart, brain, scrotum and breast. ${ }^{9}$ The filarial orchitis is rare even on extensive PubMed search (keywords: filarial, worm tunica, vaginalis, intratesticular, testis), an adult worm in the testicular tissue itself is a rare finding. Testicular tissue can be one of the site of adult parasite Wuchereriabancrofti. ${ }^{10}$

Ultrasonography ${ }^{10,11}$ may be helpful for intrascrotal pathology calcified dead worms following diethylcarbamazine (DEC) treatment presenting as specks of calcification and the "filarial dance sign" caused by the undulating movements of the live adult worms ${ }^{10,11}$ can be seen on imaging. The filarial orchitis simulate grossly with neoplastic, non-neoplastic testicular and paratesticular lesions that include non-specificorchitis, tuberculouse pididymo-orchitis malignant mesothelioma, adenomatoid tumors, mesothelioma cyst and reactive mesothelioma hyperplasia, malakoplakia, sarcoidosis and inflammatory pseudotumor diethylcarbamazine (DEC) the drug of choice for medical treatment of filariasis. As it simulates malignancy clinically, unilateral orchiectomy is the outcome in most of the cases. The testicular-sparing surgery could be a useful modality in such cases. ${ }^{3}$

\section{CONCLUSION}

Filarial orchitis may simulate clinically with neoplastic testicular lesions. The various differential diagnosis must be kept in mind when dealing with testicular swellings especially in endemic areas to avoid unnecessary orchidectomy.

\section{ACKNOWLEDGMENT}

I would like to thank co-author Mr Ashwin PS for his assistance in manuscript writing and web searches.

\section{REFERENCES}

1. Park KP. Textbook of preventive and social medicine. 22nd. Jabalpur: Banarsidas Bhanot; 2013. p. 245-251.

2. Chatterjee KD. Textbook of Parasitology, Protozoology and Helminthology in relation to Clinical Medicine. 20th ed. CBS publishers and distributors Ltd. New Delhi; India: 2009 p. 236-241.

3. Barreto SG, Rodrigues J, Pinto RGW. Filarial granuloma of the testicular tunic mimicking a testicular neoplasm: a case report. Journal of Medical Case Reports 2008;2:321.

4. Ranjan R, Choubey D, Kumar P, Besra RC, Sahu SS, Baxla RG, et al., Filarial Scrotal Tumour. Journal of Evolution of Medical and Dental Sciences. 2003;2(18):3171-3174

5. Hindi SAL, Asghar M, Hassan AA. Epididymal Filariasis in a Child: Bahrain Medical Bulletin. 2003;25:4.

6. Garg PK, Bhatt S, Kashyap B, George A, Jain BK. Genital filariasis masquerading as testicular torsion: J Vector Borne Diseases 48, June 2011, pp. 119-121.

7. PM Joshi, SR Shivde, M Mandolkar: Testicular Filariasis Masquerading as a Testicular Tumor - Case Report with Review of Literature. The Internet Journal of Surgery. 2009;23:1.

8. Basu A, Sistla SC, Verma SK, Jagdish S, Lymphadenovarix in the axilla - an unusual presentation of filariasis: Filaria Journal, 2006;5:9.

9. Behera PK, Rath PK, Panda RR, Satpathy S, Sarkar BK. Adult filarial worm in the tissue section of a breast lump: GW Indian J Surg. 2009 Aug;71(4):210-212.

10. Reddy GS, Das LK, Pani SP. The preferential site of adultWuchereriabancrofti: an ultrasound study of male asymptomatic microfilaria carriers in Pondicherry, India. Natl Med J India. 2004;17(4):195-196

11. Chaubal NG, Pradhan GM, Chaubal JN, Ramani SK. Dance of Live Adult Filarial Worms Is a Reliable Sign of Scrotal Filarial Infection. J Ultrasound Med. 2003;22:765-769. 